\title{
Is there a rationale to supplement hepatotropic factors to dogs with multiple acquired portosystemic shunts secondary to congenital portosystemic shunt attenuation?
}

\author{
Is er wetenschappelijke basis om hepatotrope factoren te supplementeren \\ aan honden met multipele verworven portosystemische shunts secundair \\ aan attenuatie van een congenitale portosystemische shunt?
}

\author{
${ }^{1}$ L.Van Acker, ${ }^{1}$ H. de Rooster, ${ }^{1}$ G. Serrano, ${ }^{1}$ D. Paepe, ${ }^{2}$ W. De Spiegelaere, ${ }^{1}$ N. Devriendt \\ ${ }^{1}$ Department of Small Animals, Faculty of Veterinary Medicine, Ghent University, \\ Salisburylaan 133, 9820 Merelbeke, Belgium \\ ${ }^{2}$ Department of Morphology, Faculty of Veterinary Medicine, Ghent University, \\ Salisburylaan 133, 9820 Merelbeke, Belgium
}

hilde.derooster@ugent.be

\begin{abstract}
$\Lambda_{\text {bistract }}$
Experimental rat models and clinical trials in human patients with liver cirrhosis show evidence that supplementation with hepatotropic factors provides therapeutic benefits. This form of support has not yet been described in dogs with multiple acquired portosystemic shunts (MAPSS) despite similarities between both pathological conditions. Especially hepatocyte growth factor (HGF) and branched chain amino acids (BCAA) deserve closer attention. High-quality vegetable rather than animal proteins have been suggested to form an excellent dietary source of BCAA, and leucine seems the best candidate for supplementation given its stimulating effects on liver function in general and on HGF secretion specifically. Research on optimal ways of administration of HGF in dogs with MAPSS secondary to congenital portosystemic shunt attenuation is necessary before clinical trials can be initiated.
\end{abstract}

\section{SAMENVATTING}

Experimentele proeven met ratten en klinische proeven met humane patiënten met levercirrose tonen aan dat supplementatie met hepatotrope factoren therapeutische voordelen biedt. Bij honden met multipele verworven portosystemische shunts werd een dergelijke supplementatie nog niet beschreven, ondanks gelijkenissen tussen beide aandoeningen. Vooral de effecten van "hepatocyte growth factor" (HGF) en vertakte keten aminozuren (BCAA) verdienen bijzondere aandacht. Hoogkwalitatieve plantaardige eiwitten, eerder dan dierlijke, worden naar voor geschoven als uitstekende bron van BCAA in de voeding. Leucine blijkt de beste kandidaat voor supplementatie gezien haar stimulatie van leverfunctie in het algemeen, en meer specifiek haar stimulatie van HGF-secretie. Verder onderzoek naar optimale toedieningswegen van HGF bij honden met multipele verworven portosystemische shunts secundair aan attenuatie van een congenitale portosystemische shunt, is nodig vooraleer klinische proeven kunnen aangevat worden.

\section{INTRODUCTION}

Multiple acquired portosystemic shunts (MAPSS) have been described in various species including humans and dogs. Traditionally, they are considered to be a collection of embryonic vessels between the portal and systemic circulation, opening as a consequence of portal hypertension (Johnson, 1987; Berent and Tobias, 2009; Buob et al., 2011; Lipinski et al., 2018; Ramirez et al., 2019). More recently, de novo formation of collateral vessels through active neoangiogenesis has been recognized as a different but 
complementary mechanism in portal hypertension (Garcia-Pras et al., 2017; Ramirez et al., 2019). Portal hypertension, or increased blood pressure in the portal vein, can be caused by an increased resistance within the portal circulation, in case of cirrhosis of the liver or portal vein thrombosis, and/or an increased portal blood volume (Berent and Tobias, 2009; Bosch et al., 2010; Buob et al., 2011; Ramirez et al., 2019). An idiopathic noncirrhotic form of portal hypertension has also been described in dogs (Bunch et al., 2001). In an experimental canine model of portal hypertension, MAPSS developed as early as four weeks after the administration of a hepatotoxin that induced hepatic fibrosis and cirrhosis (Howe et al., 2000). The emergence of MAPSS might initially normalize the portal vein pressure; however, if the underlying hepatopathy persists or progresses, portal hypertension might redevelop since progressive vasodilation of the gastrointestinal vasculature will result in a progressive increase in portal blood flow (Buob et al., 2011; Ramirez et al., 2019). Additionally, pathological vascular endothelial growth factor (VEGF)-driven angiogenesis in hypoxic splanchnic organs contributes to increased portal blood flow (Bosch et al., 2010; Ramirez et al., 2019).

Although the correlation of cirrhosis and MAPSS has been described in dogs (Boothe et al., 1996), in the majority of publications dealing with MAPSS, dogs have been described with a history of a congenital portosystemic shunt (CPSS) that has been surgically treated (Berent and Tobias, 2009; Serrano et al., 2019). The infrequent use of sensitive imaging modalities during the postoperative follow-up (Serrano et al., 2019) leaves us with an imprecise estimation of the actual incidence of MAPSS following surgical attenuation of CPSS. This might explain the lack of guidelines concerning the management of postoperative MAPSS other than the suggestion that most dogs with MAPSS most likely benefit from life-long medical management including adjusted diet, and/or lactulose and/or (temporary) antimicrobial treatment (Boothe et al., 1996). The persistent aberrant hepatic perfusion will preclude that the liver efficaciously detoxifies the blood from substances such as ammonia whereas the hepatocytes will lose their proliferative state and fail to produce adequate amounts of substances normally provided by the liver, such as albumin and clotting factors (Suter, 1975; Johnson, 1987; Kruitwagen et al., 2011; Zwingenberger et al., 2014). Hypoalbuminemia has various consequences for patients with cirrhosis and/or MAPSS. Ascites, present as a consequence of portal hypertension, can be further aggravated by hypoalbuminemia as the drop in vascular colloid osmotic pressure drives fluid into the interstitial space (Hou and Sanyal, 2009). Hypoalbuminemia also increases the severity of hepatic encephalopathy (HE), because otherwise proteinbound encephalogenic substances such as aromatic amino acids (AAA) might have easier access to the brain (Greco et al., 2000). Low albumin levels also negatively affect the antioxidant activity as well as the capacity to bind fatty acids, bilirubin, hormones, toxic substances and other ligands (Nicholson et al., 2000).

Both MAPSS and cirrhosis can be linked to impairment of liver function and other signs of chronic liver diseases (Rothuizen, 1993; Taboada and Dimski, 1995; Buob et al., 2011; Cullen and Stalker, 2015). Therefore, treatment strategies based on hepatotropic factors might, to some extent, be beneficial to dogs with MAPSS for whom, up to date, only supportive management has been considered. A canine in vivo model to screen for various putative hepatotropic growth factors identified hepatocyte growth factor (HGF), insulin-like growth factor II (IGF-II), transforming growth factor $-\alpha(\mathrm{TGF}-\alpha)$, and hepatic stimu-latory substance (HSS) as growth hormones with striking hepatotropic qualities (Francavilla et al., 1991). Whereas a lot of information is available on HGF, the paucity of studies dealing with the remainder of the factors unfortunately precludes a thorough review of their potential in dogs with MAPSS.

In this viewpoint article, HGF and BCAA will be described with respect to their activity, expected benefits and potential side effects in dogs. Hepatocyte growth factor is a protein that has mitogenic (Nakamura et al., 1984; Nakamura et al., 1989) and antiapoptotic effects (Kim et al., 2005) on hepatocytes and exogenous HGF is under research as a liver regenerative drug in humans (Mizuno and Nakamura, 2007; Nakamura and Mizuno, 2010). Likewise, the benefits of oral supplementation of BCAA in liver regeneration seem manyfold and include providing an efficient energy source (Kato et al., 1998), triggering mobilization and transformation of stem cells into hepatocytes (Okabayashi et al., 2014), and increasing the secretion of HGF (Tomiya et al., 2002; Tomiya et al., 2004) and albumin levels (Yoshida et al., 1989; Kato et al., 1991).

In dogs with MAPSS, the majority of components entering the portal vein caudal to the shunts directly reaches the systemic circulation, leaving only a small fraction of the desired substance to be delivered to first-pass effect in the liver. Therefore, apart from identifying appropriate hepatotropic factors, defining the most appropriate route of supplementation to reach the liver or reside in the liver at adequate concentration is the major challenge in dogs with MAPSS.

Before addressing available research data in dogs, a synthesis concerning data gained in rats and human patients with liver disease will be made as most research on hepatotropic factors is performed in cell lines, experimental in vivo models and in human clinical trials rather than in dogs.

\section{HEPATOCYTE GROWTH FACTOR}

Hepatocyte growth factor is produced in mesenchymal stromal cells and has mitogenic capacity; it has been identified as a protein that encourages initia- 
tion of cell division via de c-Met/HGF-receptor in a variety of cell types, including hepatocytes (Nakamura et al., 1984; Nakamura et al., 1989). Furthermore, HGF can stimulate albumin synthesis in hepatocytes as indicated by in vitro experiments of hepatocytes stimulated with recombinant human (rh)-HGF (Takehara et al., 1992) and in vivo after intravenous administration of rh-HGF to healthy rats (Yamaoka et al., 1998; Ishii et al., 1995). While HGF additionally exerts anti-apoptotic effects on hepatocytes, its proapoptotic effects on portal myofibroblasts, which are phenotypically changed hepatic stellate cells that synthesize proteins that induce fibrosis (Wu and Zern, 2000), have been proven in in vivo rat models (Kim et al., 2005). Furthermore, HGF suppresses the proliferation of those portal myofibroblasts by inhibiting DNA synthesis (Kim et al., 2005). While liver cirrhosis is generally thought to be an irreversible condition, an in vivo dimethylnitrosamine rat model of lethal liver cirrhosis has shown that resolution from liver cirrhosis is possible with remodeling of excess extracellular matrix after intraperitoneal rh-HGF administration (Kim et al., 2005). One week after daily intraperitoneal HGF injections, fibrous tissue areas were reduced by $60 \%$ compared to the fibrous tissue areas of rats given saline injections as sham controls (Kim et al., 2005).

The most common supplementation route of exogenous HGF with the aim of liver regeneration in rodents is intravenous injection of rh-HGF (Ishiki et al., 1992; Fujiwara et al., 1993). Alternatively, intraperitoneal administration of HGF (Kim et al., 2005) and transfections of the human HGF gene into skeletal muscles of rats have also been shown to effectively treat induced liver cirrhosis (Ueki et al., 1999).

Despite interest in HGF as a liver regenerative drug (Mizuno and Nakamura, 2007; Nakamura and Mizuno, 2010), clinical trials have not yet been initiated in humans.

Hepatocyte growth factor in dogs: challenges to achieve long-term effects

The effect of exogenous rh-HGF on liver regeneration has been studied in experimental beagle dogs subjected to left-sided portal branch ligation (Ueno et al., 1996). Two days after this procedure, rh-HGF was administered directly into the portal vein through an intraportal catheter via a small ileocolic vein, to avoid any influence on organs other than the liver (Ueno et al., 1996). Two weeks later, the weight of both ligated and nonligated liver lobes was significantly increased compared to nontreated controls. Hepatocyte hypertrophy was observed in the non-ligated lobes; however, there was no noticeable increase in hepatocyte size in the lobes lacking portal blood flow (Ueno et al., 1996).

In dogs with CPSS - studied as a spontaneous model for hypoplastic liver disease - treated twice daily with recombinant feline HGF administered in the jugular vein through a central venous catheter, considerable liver growth was observed during three weeks of intravenous treatment (Kruitwagen et al., 2011). Although liver volume did increase significantly during the period of HGF administration, the treatment result was only temporary, suggesting that lifelong HGF supplementation would be needed to result in sustained liver growth (Kruitwagen et al., 2011). Importantly, the increase in liver size did not result in normalization of the serum albumin levels, neither did liver function tests improve, probably because portal perfusion did not change in the presence of the CPSS (Kruitwagen et al., 2011).

Since patients with MAPSS due to prehepatic or hepatic pathology are often characterized by an underdeveloped liver, the idea of HGF supplementation to those patients triggers further research. Similar to the situation in dogs with a CPSS (Kruitwagen et al., 2011), it is unlikely that intravenous HGF supplementation would have a positive effect on the albumin concentrations in dogs with MAPSS. Nevertheless, it is certainly interesting to explore alternative ways of administration and/or potentially alternative forms of HGF such as prolonged release formulations of HGF analogues. Administration of rh-HGF is well tolerated by dogs (Ueno et al., 1996), whereas recombinant feline HGF induces an immunological reaction in dogs (Kruitwagen et al., 2011). Producing large amounts of rh-HGF for therapeutic purposes would not be a limiting factor since it can be provided by ex vivo formation in a plasmid vector by selection and cloning processes (Strain et al., 1991), which is presumed to be similar for recombinant canine HGF. A possible alternative to rh-HGF would be the administration of drugs which stimulate endogenous HGF release (Borawski et al., 2007) and can be administered orally, eliminating the necessity of a venous catheter. An additional challenge in dogs with MAPSS would be whether the hypoperfused hepatocytes can be sufficiently triggered. Likewise, it would be interesting to explore the role of pro-inflammatory cytokines and humoral mediators in the production of HGF as disease-modulating agents (Nakamura and Mizuno, 2010). In this way, alternative pathways to ensure higher endogenous HGF levels may be ascertained.

\section{BRANCHED CHAIN AMINO ACIDS}

Branched chain amino acids, such as leucine, isoleucine and valine, are essential amino acids in mammals, meaning - in the strict sense - that they form a dietary necessity and cannot be synthesized de novo (Reeds, 2000). However, they can be synthesized by transamination of their branched chain keto acid analogues; yet, these keto acid analogues were originally derived from the BCAA themselves (Reeds, 2000). It is therefore mandatory to provide sufficient dietary intake of BCAA.

In humans with liver cirrhosis, BCAA offer a high- 
er energy efficacy than glucose or fatty acids (Kato et al., 1998). In several studies in human patients and rats undergoing partial hepatectomy, an effect of BCAA supplementation has also been reported on liver regeneration (Kim et al., 2011; Beppu et al., 2015). Supplementation of BCAA is also known to increase albumin concentrations in humans with liver cirrhosis (Yoshida et al., 1989; Kato et al., 1991).

In humans with liver disease resulting in hyperammonemia, plasma concentrations of BCAA are severely decreased (Soeters and Fischer, 1976) because these amino acids are intensely consumed by an alternate route of ammonia detoxification, forming glutamine in muscle and brain tissue (Bachmann et al., 2004; Holecek et al., 2011). In case of malnutrition, muscle tissue catabolism is increased, disturbing this alternate route. The brain then becomes the main source of glutamine synthesis, leading to astrocyte swelling and more severe HE (Brusilow and Traystman, 1986; Bachmann et al., 2004; Cohn and Roth, 2004). Additionally, the lack of ammonia detoxification in muscle tissue leads to more accumulation of ammonia in the blood, which will further increase utilization of BCAA, causing even lower BCAA levels (Bachmann et al., 2004). In order to maintain lean body mass and thus preserve sufficient glutamine synthesis in muscle tissue to avoid this vicious circle, patients with liver cirrhosis must be provided with a diet containing high quality proteins (Plauth et al., 1997a; Plauth et al., 1997b; Merli and Riggio, 2009). In dogs with PSS, daily ingestion of $2.11 \mathrm{~g}$ crude protein $/ \mathrm{kg}$ body weight with an $80 \%$ or greater availability is recommended to adequately maintain body protein reserves without inciting HE (Laflamme et al., 1993). Vegetable proteins are suggested to result in less severe HE compared to animal proteins, since they ameliorate the nitrogen balance and contain higher levels of BCAA (Keshavarzian et al., 1984; Bianchi et al., 1993).

In many studies in human patients with liver cirrhosis and HE, clinical improvement after administration of BCAA-enriched diets has been reported (Marchesini et al., 1990; Bianchi et al., 1992; Plauth et al., 1993). It must be noted that the supplementation route can strongly influence the effects of BCAA. Although there is no complete certainty on preferable supplementation routes, oral administration of BCAA (whether or not in combination with lactulose) has been shown to significantly improve the manifestation of HE in humans with liver cirrhosis, whereas intravenous administration seems to have lesser effects on HE (Gluud et al., 2013a; Gluud et al., 2013b). There are indications that the amelioration of HE signs is explained by an increased ratio of BCAA to AAA, such as phenylalanine, tryptophan and tyrosine, rather than by the reduction of blood ammonia levels (Tajiri and Shimizu, 2013). Next to the route, the timing of BCAA supplementation influences the effect size; administration of a double dose of BCAA before bedtime versus one dose at lunch and one at dinner improves the serum albumin levels, even in refractory cirrhotic patients (Fukushima et al., 2003).

Leucine seems to be the most suitable candidate for supplementation in case of liver disease, as has been put forward in studies on hepatic stellate cell culture and in rats in vivo, because it also stimulates the secretion of HGF, in contrast to isoleucine or valine (Tomiya et al., 2002; Tomiya et al., 2004). In young growing rats, intraperitoneal injections of leucine increase HGF secretion and, after repeated treatments, an increase in liver weight has been observed (Tomiya et al., 2004). Additionally, adult healthy rats have shown increased serum albumin concentrations, indicating a clear improvement in liver function (Tomiya et al., 2004). Leucine is particularly interesting since it does not form a complex with albumin mRNA, leaving albumin mRNA free for translation (Kuwahata et al., 2008). The effects of leucine supplementation in rats with liver cirrhosis remain to be studied.

Do branched chain amino acids have hepatotropic properties in dogs with liver disease?

In several studies, a reduced ratio of BCAA to AAA has been confirmed in dogs with liver disease (Aguirre et al., 1974; Joyeux et al., 1994; Awad et al., 2000). Nevertheless, there is no literature available on the effects of BCAA supplementation in dogs with severe hepatopathy, with the exception of one experimental cross-over study, in which a portocaval shunt was created followed by partial hepatectomy (Meyer et al., 1999). In that study, the dogs showed a significant decrease in BCAA, a concomitant rise in AAA, hyperammonemia, and obvious signs of HE after these interventions (Meyer et al., 1999). After this model had been created, the dogs received either a diet with high BCAA/AAA ratio or a diet with low BCAA/AAA ratio; both diets contained the same protein amount and were fed ad libitum (Meyer et al., 1999). Unexpectedly, the dogs had a lower plasma ammonia concentration when eating the low BCAA/ AAA ratio diet, of which they consumed significantly more than of the high ratio diet. In that study, it was concluded that not the proportion of amino acids in a diet but rather the total protein intake, and therefore, the overall improved nutritional state, could possibly be responsible for decreasing HE symptoms (Meyer et al., 1999). Remarkably, there was no normalization of the BCAA/AAA ratio in the dogs given the high ratio diet, suggesting a higher peripheral utilization of BCAA (Meyer et al., 1999). Interestingly, Proot et al. (1999) compared the use of a soy protein diet versus a poultry protein diet in dogs with PSS and concluded that the significantly lower blood ammonia concentrations after the soy protein diet were more likely to be related to the higher digestibility of that protein source than to its better BCAA/AAA ratio. In a study in rats with experimentally induced PSS, it has been 
documented that a soy protein diet prevents hypermethionemia, lowering the risk of ammonia toxic effects (Shimooka et al., 2006). Further research remains necessary to evaluate whether or not BCAA alleviate clinical signs of $\mathrm{HE}$ and have hepatotropic properties in dogs with severe liver disease and/or MAPSS. In particular, the effects of leucine on HGF secretion and albumin concentrations deserve attention.

\section{CONCLUSION}

Dogs with MAPSS should continue to receive a diet based on high-quality proteins as a source of BCAA, and a good nutritional status should be pursued to minimize clinical signs related to HE. In studies in humans with severe liver disease, various positive effects of BCAA supplementation have been confirmed; not only are HE signs abated and albumin synthesis stimulated, there are also indications for liver regeneration. Oral leucine seems to be particularly promising because it might stimulate HGF secretion. Up till now, there are no similar studies in dogs with liver disease, let alone in dogs with MAPSS. However, the positive results in human medicine certainly appeal for further investigation in those dogs.

A life-long treatment with systemic HGF supplementation may potentially ensure sustained liver growth, despite the abnormal portal circulation in dogs with MAPSS. However, repeated intravenous supplementation of HGF is not an appropriate clinical approach in veterinary medicine. Administration of drugs that stimulate endogenous HGF secretion may form an interesting alternative. In a second step, it should still be demonstrated whether long term administration of HGF will also ameliorate liver function in addition to liver growth.

\section{CONFLICT OF INTEREST}

No conflicts of interest have been declared. No financial or other support was used in this study.

\section{REFERENCES}

Aguirre, A., Yoshimura, N., Westman T., Fischer, J.E. (1974). Plasma amino acids in dogs with two experimental forms of liver damage. Journal of Surgical Research $16,339-345$

Awad, S.S., Hemmila, M.R., Soldes, O.S., Sawada, S., Rich, P.B., Mahler, S., Gargulinski, M., Hirschl, L.B., Bartlett, L.H. (2000). A novel stable reproducible model of hepatic failure in canines. Journal of Surgical Research 94, 167-171.

Bachmann, C., Braissant, O., Villard, A.M., Boulat, O., Henry, H. (2004). Ammonia toxicity to the brain and creatine. Molecular Genetics and Metabolism 81, 52-57.

Beppu, T., Nitta, H., Hayashi, H., Imai, K., Okabe, H., Na- kagawa, S., Hashimoto, D., Chikamoto, A., Ishiko, T., Yoshida, M., Yamashita, Y., Baba, H. (2015). Effect of branched-chain amino acid supplementation on functional liver regeneration in patients undergoing portal vein embolization and sequential hepatectomy: a randomized controlled trial. Journal of Gastroenterology 50, $1197-$ 1205.

Berent, A.C., Tobias, K.M. (2009). Portosystemic vascular anomalies. Veterinary Clinics of North America: Small Animal Practice 39, 513-541.

Bianchi, G.P., Marchesini, G., Fabbri, A., Rondelli, A., Bugianesi, E., Zoli, M., Pisi, E. (1993). Vegetable versus animal protein diet in cirrhotic patients with chronic encephalopathy. A randomized cross-over comparison. Journal of Internal Medicine 233, 385-392.

Bianchi, G.P., Marchesini, G., Zoli, M., Abbiati, R., Ferrario, E., Fabbri, A., Pisi, E. (1992). Oral BCAA supplementation in cirrhosis with chronic encephalopathy: Effects on prolactin and estradiol levels. Hepatogastroenterology 39, 443-446.

Boothe, H.W., Howe, L.M., Edwards, J.F., Slater, M.R. (1996). Multiple extrahepatic shunts in dogs: 30 cases (1981-1993). Journal of the American Veterinary Medical Association 208, 1849-1854.

Borawski, J., Dubowski, M., Pawlak, K., Mysliwiec, M. (2007). Sulodexide induces hepatocyte growth factor release in humans. European Journal of Pharmacology $558,167-171$.

Bosch, J., Abraldes, J.G., Fernández, M., Garcia-Pagán, J.C. (2010). Hepatic endothelial dysfunction and abnormal angiogenesis: New targets in the treatment of portal hypertension. Journal of Hepatology 53, 558-567.

Brusilow, S.W., Traystman, R. (1986). Hepatic encephalopathy. New England Journal of Medicine 314, 786-787.

Bunch, S.E., Johnson, S.E., Cullen, J.M. (2001). Idiopathic noncirrhotic portal hypertension in dogs: 33 cases (19821998). Journal of the American Veterinary Medicine Association 218, 392-399.

Buob, S., Johnston, A.N., Webster, C.R.L. (2011). Portal hypertension: pathophysiology, diagnosis, and treatment. Journal of Veterinary Internal Medicine 25, 169-186.

Cohn, R.M., Roth, K. S. (2004). Hyperammonemia, bane of the brain. Clinical Pediatrics 43, 683-689.

Cullen, J.M., Stalker, M.J. (2015). Liver and Biliary System. In: Maxie M.G. (editor). Jubb, Kennedy, and Palmer's Pathology of Domestic Animals. Sixth edition, Saunders Elsevier, Philadelphia, p. 258-352.

Francavilla, A., Starzi, T.E., Porter, K., Foglieni, C.S., Michalopoulos, G.K., Carrieri, G., Trejo, J., Azzarone, A., Barone, M., Zeng, Q.H. (1991). Screening for candidate hepatic growth factors by selective portal infusion after canine Eck's fistula. Hepatology 14, 665-670.

Fujiwara, K., Nagoshi, S., Ohno, A., Hirata, K., Ohta, Y., Mochida, S., Tomiya, T., Higashio, K., Kurokawa, K. (1993). Stimulation of liver growth by exogenous human hepatocyte growth factor in normal and partially hepatectomized rats. Hepatology 18, 1443-1449.

Fukushima, H., Miwa, Y., Ida, E., Kuriyama, S., Toda, K., Shimomura, Y., Sugiyama, A., Sugihara, J., Tomita, E., Moriwaki, H. (2003). Nocturnal branched-chain amino acid administration improves protein metabolism in patients with liver cirrhosis: comparison with daytime administration. Journal of Parenteral and Enteral Nutrition 27, 315-322.

Garcia-Pras, E., Gallego, J., Coch, L., Mejias, M., Fernan- 
dez-Miranda, G., Pardal, R., Bosch, J., Mendez, R., Fernandez, M. (2017). Role and therapeutic potential of vascular stem/progenitor cells in pathological neovascularization during chronic portal hypertension. Gut 66 , 1306-1320.

Gluud, L.L., Dam, G., Borre, M., Les, I., Cordoba, J., Marchesini, G., Aagaard, N.K., Vilstrup, H. (2013a). Lactulose, rifaximin or branched chain amino acids for hepatic encephalopathy: what is the evidence? Metabolic Brain Disease 28, 221-225.

Gluud, L.L., Dam, G., Borre, M., Les, I., Cordoba, J., Marchesini, G., Aagaard, N.K., Risum, N., Vilstrup, H. (2013b). Oral branched-chain amino acids have a beneficial effect on manifestations of hepatic encephalopathy in a systematic review with meta-analyses of randomized controlled trials. The Journal of Nutrition 143, 12631268.

Greco, A.V., Mingrone, G., Favuzzi, A., Bertuzzi, A., Gandolfi, A., Desmet, R., Vanholder, R., Gasbarrini, G. (2000). Subclinical hepatic encephalopathy: role of tryptophan binding to albumin and the competition with indole-3-acetic acid. Journal of Investigative Medicine 48, 274-280.

Holecek, M., Kandar, R., Sispera, L., Kovarik, M. (2011). Acute hyperammonemia activates branched-chain amino acid catabolism and decreases their extracellular concentrations: different sensitivity of red and white muscle. Amino Acids 40, 575-584.

Hou, W., Sanyal, A.J. (2009). Ascites: Diagnosis and management. Medical Clinics of North America 93, 801-817.

Howe, L.M., Boothe, H.W. Jr., Miller, M.W., Boothe, D.M. (2000). A canine model of multiple portosystemic shunting. Journal of Investigative Surgery 13, 45-57.

Ishii, T., Sato, M., Sudo, K., Suzuki, M., Nakai, H., Hishida, T., Niwa, T., Umezu, K., Yuasa, S. (1995). Hepatocyte growth factor stimulates liver regeneration and elevates blood protein level in normal and partially hepatectomized rats. Journal of Biochemistry 117, 1105-1112.

Ishiki, Y., Ohnishi, H., Muto, Y., Matsumoto, K., Nakamura, T. (1992). Direct evidence that hepatocyte growth factor is a hepatotrophic factor for liver regeneration and has a potent antihepatitic effect in vivo. Hepatology 16, 1227-1235.

Johnson, S.E. (1987). Portal hypertension. Part I. Pathophysiology and clinical consequences. Compendium on Continuing Education for the Practicing Veterinarian 9, 741-748.

Joyeux, H., Matias, J., Saint-Aubert, B., Astre, C., Gouttebel, M.C., Vedrenne, J.B., Deneux, L. (1994). Serum marker of the functional hepatic mass after extensive hepatectomy. The branched/aromatic amino acid ratio. Experimental and clinical studies. Chirurgie 120, 283288.

Kato, M., Miwa, Y., Tajika, M., Hiraoka, T., Muto, Y., Moriwaki, H. (1998). Preferential use of branched-chain amino acids as an energy substrate in patients with liver cirrhosis. Internal Medicine 37, 429-434.

Kato, M., Yoshida, T., Moriwaki, H., Mut, Y. (1991). Effect of branched-chain amino acid (BCAA) enriched-nutrient mixture on albumin metabolism in cirrhotic patients. Acta Hepatologica Japonica 32, 692-699.

Keshavarzian, A., Meek, J., Sutton, C., Emery, V.M., Hughes, E.A., Hodgson, H.J. (1984). Dietary protein supplementation from vegetable sources in the management of chronic portal systemic encephalopathy. Ameri- can Journal of Gastroenterology 79, 945-949.

Kim, S.J., Kim, D.G., Lee, M.D. (2011). Effects of branched-chain amino acid infusions on liver regeneration and plasma amino acid patterns in partially hepatectomized rats. Hepatogastroenterology 58, 1280-1285.

Kim, W.H., Matsumoto, K., Bessho, K., Nakamura, T. (2005). Growth inhibition and apoptosis in liver myofibroblasts promoted by hepatocyte growth factor leads to resolution from liver cirrhosis. American Journal of Pathology 166, 1017-1028.

Kruitwagen, H.S., Arends, B., Spee, B., Brinkhof, B., van den Ingh, T.S.G.A.M., Rutten, V.P.M.G., Penning, L.C., Roskams, T., Rothuizen, J. (2011). Recombinant hepatocyte growth factor treatment in a canine model of congenital liver hypoplasia. Liver International 31, 940-949.

Kuwahata, M., Yoshimura, T., Sawai, Y., Amano, S., Tomoe, Y., Segawa, H., Tutsumi, S., Ito, M., Ishizaki, S., Ijichi, C., Sonaka, I., Oka, T., Miyamoto, K. (2008). Localization of polypyrimidine-tract-binding protein is involved in the regulation of albumin synthesis by branched-chain amino acids in HepG2 cells. The Journal of Nutritional Biochemistry 19, 438-447.

Laflamme, D.P., Allen, S.W., Huber, T.L. (1993). Apparent dietary protein requirements of dogs with portosystemic shunt. American Journal of Veterinary Research 54, 719723.

Lipinski, M., Saborowski, M., Heidrich, B., Attia, D., Kasten, P., Manns, M.P., Gebel, M., Potthoff, A. (2018). Clinical characteristics of patients with liver cirrhosis and spontaneous portosystemic shunts detected by ultrasound in a tertiary care and transplantation centre. Scandinavian Journal of Gastroeneterology 53, 1107-1113.

Marchesini, G., Dioguardi, F.S., Bianchi, G.P., Zoli, M., Bellati, G., Roffi, L., Martines, D., Abbiati, R. (1990). Long-term oral branched-chain amino acid treatment in chronic hepatic encephalopathy. A randomized doubleblind, casein-controlled study. Journal of Hepatology 11, 92-101.

Merli, M., Riggio, O. (2009). Dietary and nutritional indications in hepatic encephalopathy. Metabolic Brain Disease 24, 211-221.

Meyer, H.P., Chamuleau, R.A., Legemate, D.A., Mol, J.A., Rothuizen, J. (1999). Effects of a branched-chain amino acid-enriched diet on chronic hepatic encephalopathy in dogs. Metabolic Brain Disease 14, 103-115.

Mizuno, S., Nakamura, T. (2007). Hepatocyte growth factor: a regenerative drug for acute hepatitis and liver cirrhosis. Regenerative Medicine 2, 161-170.

Nakamura, T., Mizuno, S. (2010). The discovery of Hepatocyte Growth Factor (HGF) and its significance for cell biology, life sciences and clinical medicine. In: Proceedings of the Japan Academy, Series B Physical and Biological Sciences 86, 588-610.

Nakamura, T., Nawa, K., Ichihara, A. (1984). Partial purification and characterization of hepatocyte growth factor from serum of hepatectomized rats. Biochemical and Biophysical Research Communications 122, 1450-1459.

Nakamura, T., Nishizawa, T., Hagiya, M., Seki, T., Shimonishi, M., Sugimura, A., Tashiro, K., Shimizu, S. (1989). Molecular cloning and expression of human hepatocyte growth factor. Nature 342, 440-443.

Nicholson, J.P., Wolmarans, M.R., Park, G.R. (2000). The role of albumin in critical illness. British Journal of Anaesthesia 85, 599-610.

Okabayashi, T., Shima, Y., Sumiyoshi, T., Kozuki, A., 
Iiyama, T., Tokumaru, T., Namikawa, T., Sugimoto, T., Takezaki, Y., Maeda, H., Kobayashi, M., Hanazaki, K. (2014). Extrahepatic stem cells mobilized from the bone marrow by the supplementation of branched-chain amino acids ameliorate liver regeneration in an animal model. Journal of Gastroenterology and Hepatology 29, 870877.

Plauth, M., Egberts, E.H., Hamster, W., Török, M., Müller, P.H., Brand, O., Fürst, P., Dölle, W. (1993). Long-term treatment of latent portosystemic encephalopathy with branched-chain amino acids. A double-blind placebocontrolled crossover study. Journal of Hepatology 17, 308-314.

Plauth, M., Merli, M., Kondrup, J. (1997a). Management of hepatic encephalopathy. New England Journal of Medicine 337, 1921-1922.

Plauth, M., Merli, M., Kondrup, J., Weimann, A., Ferenci, P., Müller, M.J. (1997b). ESPEN guidelines for nutrition in liver disease and transplantation. Clinical Nutrition 16, 43-55.

Proot, S., Biourge, V., Teske, E., Rothuizen, J. (2009). Soy protein isolate versus meat-based low-protein diet for dogs with congenital portosystemic shunts. Journal of Veterinary Internal Medicine 23, 794-800.

Ramirez, M., Pell, N., Mejias, M., Fernandez, M. (2019). Pericytes in the gut. In: Birbrair A. (editor). Pericyte Biology in Different Organs. Springer Nature Switzerland, Cham, p. 73-100.

Reeds, P.J. (2000). Dispensable and indispensable amino acids for humans. The Journal of Nutrition 130, 18351840.

Rothuizen, J. (1993). Portosystemic hepatic encephalopathy related with congenital and acquired hepatopathies in the dog. Advances in Veterinary Science and Comparative Medicine 37, 403-416.

Serrano, G., Charalambous, M., Devriendt, N., de Rooster, H., Mortier, F., Paepe, D. (2019). Treatment of congenital extrahepatic portosystemic shunts in dogs: A systematic review and meta-analysis. Journal of Veterinary Internal Medicine 33, 1865-1879.

Shimooka, R., Yasuhiro, K., Chiba, N., Tanaka, J., Rokutan, K., Furochi, H., Hirassaka, K., Nikawa, T., Kisshi, K. (2006). Soy protein diet prevents hypermethioninemia caused by portacaval shunt in rats. Journal of Medical Investigation 53, 255-263.

Soeters, P.B., Fischer, J. E. (1976). Insulin, glucagon, aminoacid imbalance, and hepatic encephalopathy. Lancet 2 , 880-882.

Strain, A.J., Ismail, T., Tsubouchi, H., Arakaki, N., Hishida, T., Kitamura, M., Daikuhara, Y., McMaster, P. (1991). Native and recombinant human hepatocyte growth factors are highly potent promoters of DNA synthesis in both human and rat hepatocytes. The Journal of Clinical Investigation 87, 1853-1857.

Suter, P.F. (1975). Porta vein anomalies in the dog: their angiographic diagnosis. Veterinary Radiology 16, 84-97.

Taboada, J., Dimski, D.S. (1995). Hepatic encephalopathy: clinical signs, pathogenesis, and treatment. The Veterinary Clinics of North America. Small Animal Practice 25, 337-355.

Tajiri, K., Shimizu, Y. (2013). Branched-chain amino acids in liver disease. World Journal of Gastroenterology 19, 7620-7629.

Takehara, T., Matsumoto, K., Nakamura, T. (1992). Cell density-dependent regulation of albumin synthesis and DNA synthesis in rat hepatocytes by hepatocyte growth factor. The Journal of Biochemistry 112, 330-334.

Tomiya, T., Inoue, Y., Yanase, M., Arai, M., Ikeda, H., Tejima, K., Nagashima, K., Nishikawa, T., Fujiwara, K. (2002). Leucine stimulates the secretion of hepatocyte growth factor by hepatic stellate cells. Biochemical and Biophysical Research Communications 297, 1108-1111.

Tomiya, T., Inoue, Y., Yanase, M., Arai, M., Ikeda, H., Tejima, K., Nagashima, K., Nishikawa, T., Watanabe, N., Omata, M., Fujiwara, K. (2004). Treatment with leucine stimulates the production of hepatocyte growth factor in vivo. Biochemical and Biophysical Research Communications 322, 772-777.

Ueki, T., Kaneda, Y., Tsutsui, H., Nakanishi, K., Sawa, Y., Morishita, R., Matsumoto, K., Nakamura, T., Takahashi, H., Okamoto, E., Fujimoto, J. (1999). Hepatocyte growth factor gene therapy of liver cirrhosis in rats. Nature Medicine 5, 226-230.

Ueno, S., Aikou, T., Tanabe, G., Kobayashi, Y., Hamanoue, M., Mitsue, S., Kawaida, K., Nakamura, T. (1996). Exogenous hepatocyte growth factor markedly stimulates liver regeneration following portal branch ligation in dogs. Cancer Chemotherapy and Pharmacology 38, 233-237.

Wu, J., Zern, M.A. (2000). Hepatic stellate cells: a target for the treatment of liver fibrosis. Journal of Gastroenterology 35, 665-672.

Yamaoka, M., Hirata, K., Ogata, I., Tomiya, T., Nagoshi, S., Mochida, S., Fujiwara, K. (1998). Enhancement of albumin production by hepatocyte growth factor in rat hepatocytes: distinction in mode of action from stimulation of DNA synthesis. Liver 18, 52-59.

Yoshida, T., Muto, Y., Moriwaki, H., Yamato, M. (1989). Effect of long-term oral supplementation with branchedchain amino acid granules on the prognosis of liver cirrhosis. Gastroenterologica Japonica 24, 692-698.

Zwingenberger, A.L., Daniel, L., Steffey, M.A., Hayhew, P.D., Mayhew, K.N., Culp, W.T.N., Hunt, G.B. (2014). Correlation between liver volume, portal vascular anatomy, and hepatic perfusion in dogs with congenital portosystemic shunt before and after placement of ameroid constrictors. Veterinary Surgery 43, 926-934.

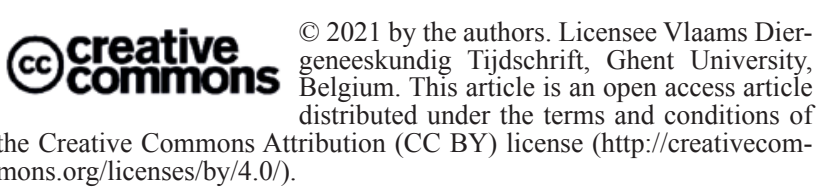

